\title{
The Development of Three-Dimensional Symbols in Chinese Freehand Brushwork and Its Contemporary Value
}

\author{
Hanying Sun $^{1, *}$ \\ ${ }^{1}$ Neuroscience and Intelligent Media Institute, Communication University of China, Beijing 100024, China \\ *Corresponding author. Email: 351325528@qq.com
}

\begin{abstract}
In the era of rapid development of science and technology, the development of Chinese freehand brushwork must be compatible with human visual cognition in order to meet the aesthetic expectations of the present audience. The three-dimensional expression should not be the standard to differentiate traditional Chinese painting and western painting. Since ancient times, Chinese artists have been exploring the form of three-dimensional expression. Modern painters break through the limitation of painting materials and techniques, and combine freehand brushwork and realism perfectly. This kind of expression not only expands the artistic conception of traditional Chinese painting, but also realizes the interaction of multi-sensory communication, which brings good aesthetic experience to the viewers. It promotes the development and innovation of traditional freehand brushwork to modern freehand brushwork and highlights the value of the times.
\end{abstract}

Keywords: traditional Chinese painting, Chinese freehand brushwork, three-dimensional symbols, aesthetic

expectation

\section{INTRODUCTION}

Since the pre-Qin period, China has produced the rudiment of painting, which is one of the beautiful treasures of the Chinese nation, so it is the responsibility of contemporary artists to inherit the traditional skill, break through boldly, and create a new Chinese painting symbols that keep pace with the times and bring good aesthetic experience to the viewers. However, for a long time, the concept of flat expression of Chinese freehand brushwork has made people follow the old routine and a large part of the people dare not leapfrog the pond.

In the book Pictures and Visuality in Early Modern China, Craig Clunas believes that the dichotomy of "traditional Chinese painting" and "western painting" is completely useless. ${ }^{1} \mathrm{He}$ also questioned the idea that realism was completely western, which is quite different with William Norman Bryson, who believed that there were complete and absolute differences between traditional Chinese paintings and European paintings from the beginning. The "three dimensional" and "plane" belong to the means of expression of

Craig Clunas, Trans by Huang Xiaojuan: Pictures and Visuality in Early Modern China, Peking University Press, 2011, Beijing, China, PIX painting. Why do they become the essential difference between eastern and western painting? From the perspective of visual expression, "three-dimensional" and "plane" belong to the expressive techniques of painting. How did they become the essential differences between eastern and western paintings?

The development of three-dimensional symbols in Chinese freehand brushwork is the inevitable product of the development of painting skill. At present, freehand brushwork in traditional Chinese painting has broken through the limitation of materials, techniques and expressive forms. It pays attention to the transmission of artistic conception and emotion, and pursues the social value and practical application function of art. It breaks through the boundaries, perfectly integrates freehand brushwork and realism, shortens the distance between human and nature, increases the interaction of people's multi-sensory communication, and makes the viewer have a good immersive experience. From the perspective of human physiological structure, human vision can have a strong perception of threedimensional images, which helps humans to stay away from incomprehensible and meaningless conjectures and be better influenced by art.

Gong $\mathrm{Bi}$ is a traditional Chinese realistic painting characterized by fine brushwork and close attention to detail. But the layer of halo dye takes a lot of time, the 
technique is simple and lack of emotional catharsis and the passion brought by the splashing ink with brush. Traditional freehand brushwork only pursues the effect of brush and ink, but lacks the appeal brought by the three-dimensional image. Three-dimensional freehand brushwork is developed by drawing on the advantages of ancient and modern Chinese and foreign paintings, it is a new form that many young and middle-aged artists are pursuing and exploring. It is an inevitable bright future for traditional Chinese painting.

\section{Phenomena In CURRENT Chinese FREEHAND BRUSHWORK}

Mr. Lin Fengmian said in the article "The Future of Traditional Chinese Painting We Hope For" that "Today's traditional Chinese painting forgets time, which refers to the conservatism of the tradition, the imitation of the ancients and the plagiarism of the predecessors. Art is for the painters to express his or her thoughts and feelings. Although the painter's thoughts and feelings are personal, but the painter belongs to those times, so the changes of the times should be directly reflected in the content and skills of traditional Chinese painting. If the content and skills of painting cannot change with the times, just following the people of thousands of years ago, at least it can be said that the art could not express the painter's personal thoughts and feelings." ${ }^{2}$ Today traditional Chinese painting is still faced with two kinds of problems: some people stick to the tradition and do not seek change, believing that only by learning the tradition can they keep the lifeblood; the other part of people denies the tradition, abandons the image building, and applies it abstractly at will. This kind of work can't be understood by others, or confused by themselves, which makes people feel puzzled. They think that the work that can't be understand is the perfect art. The outstanding feature of traditional Chinese painting is to show the inner spiritual temperament, which is also the accumulation of painter's memory, experience, feelings, thoughts and other elements.

The development prospect of traditional Chinese painting must be the organic combination of art and science. Traditional Chinese painting not only has artistic appreciation value, but also plays an important role in promoting the development of human's intelligence. Many areas of the human brain are involved in the whole painting process, especially the hippocampus and parahippocampal gyrus. ${ }^{3}$ The long-

Lin Fengmian "The Future of the Traditional Chinese Painting We Hope For" in Shao Qi, Sun Haiyan: A collection of discussions on Traditional Chinese painting in the 20th Century, Shanghai, Shanghai Calligraphy \& Painting Publishing House, 2008, P60.

Hu Jun:" Research on the Brain Neural Mechanism of Literary and Artistic Creation". Social Science. 2020,(2) term memory formed by the memorial painting skill of traditional Chinese painting can play a beneficial role in the development of the brain. In the western painting work, it takes the instantaneous memory as the leading factor and follows the scientific concept to create a three-dimensional and realistic artistic image. The three-dimensional performance techniques of Chinese freehand brushwork draw on the advantages of Chinese and western painting, and at the same time awaken the long-term memory and short-term memory cells in the human brain, which has a positive role in promoting brain function. In addition, due to the same visual physiological structure of human being, the threedimensional image can make the eyes feel more comfortable, thus bringing relaxed "pleasure" to the body and the mind.

\section{THE HISTORICAL ORIGIN OF CHINESE FREEHAND BRUSHWORK AND THE INNOVATION WITH TIMES}

The expression form of "plane" of Chinese freehand brushwork is only one of the theories of historical painting style. Throughout the long history of traditional Chinese painting, it is obvious that the related theories had existed for a long time. In fact, the three-dimensional form of expression has not been developed due to many factors, among which the most important is the disconnection between painting and science, and the over emphasis on image concept, which makes the painter's subjective image instead of the objective natural image, so that Chinese freehand painting is bound in the concept of flat. However, in the history of traditional Chinese painting, the works of many outstanding painters and theorists who pursued the expression of three-dimensional feeling radiated brilliant light at that time.

As early as in the Northern and Southern Dynasties(420-589AD), Zong Bing ${ }^{4}$ elaborated the principle of perspective in the book The Preface of Chinese Landscape Painting, which was 1000 years earlier than the birth of western perspective. Not only Zong Bing, but also Wang Wei ${ }^{5}$ of Tang Dynasty(618907AD)and Guo $\mathrm{Xi}^{6}$ of Northern Song Dynasty(9601127AD) had related discussions. Perspective can make the whole work have a three-dimensional sense, it is the enlightenment of the three-dimensional concept of Chinese painting modeling, and it has laid a theoretical foundation for the creation of three-dimensional image.

In history, many painters have been tirelessly pursuing the three-dimensional expression of traditional

\footnotetext{
4 Zong Bing, a painter in the Southern Dynasty, was the author of the book The Preface of Chinese Landscape Painting.

Wang Wei was a poet and painter in Tang Dynasty.

Guo Xi was an outstanding painter and painting theorist in the Northern Song Dynasty.
} 
Chinese painting. Zhang Sengyao, a famous painter in the Northern and Southern Dynasties, painted "concave and convex flowers" in temples with a significant threedimensional sense. Because this painting skill greatly enhanced the expressiveness and appeal of painting art, it played a great role in promoting the spread of religious culture at that time. This shows that the visual impact of three-dimensional sense can give good artistic appeal to the audience, and it has a great impact on the three-dimensional image of Gongbi ${ }^{7}$ painting. After the Qing Dynasty painter Lang shining(Giuseppe Castiglione) came to China from Italy, meticulous painting achieved unprecedented three-dimensional form of expression. However, the freehand brushwork works on the rice paper, which has strong water absorption and is difficult to control the shape. Especially for the freehand flower and bird painting, the three-dimensional expression techniques are in a dilemma. Some people who follow the beaten track, believe that the three-dimensional sense and the light and shadow can not belong to traditional Chinese painting. The outstanding work of figure painting "The Refugees" painted by the famous painter Jiang Zhaohe has also been looked down upon. However, with the rapid development of modern science and technology, painting skill should also be developed with people's ideas. The diversified development of freehand brushwork symbols is inevitable. Through the continuous exploration of many modern painters, the three-dimensional symbol has become an important development direction of modern freehand brushwork. For example, in the work "High Mountains and Blessed Flowing Water"(see "Fig. 1") shows a strong sense of order. The image is both freehand and realistic. The blooming peony fully shows the elegant temperament and prosperous artistic conception.

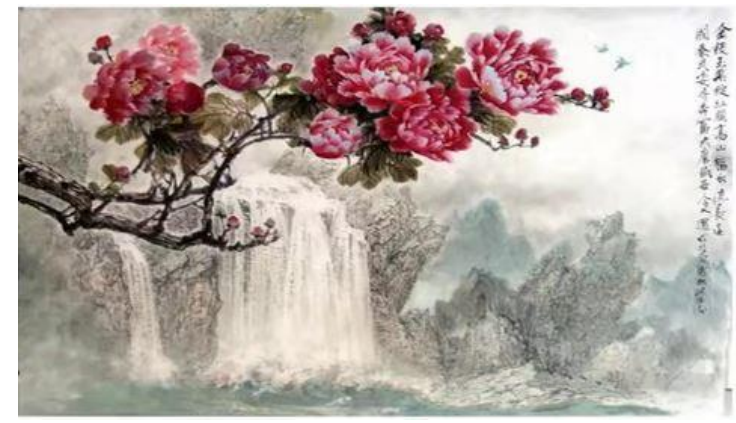

Fig. 1. Sun Yude ${ }^{8}$ High Mountains and Blessed Flowing Water.

The author depicts the peonies in full bloom delivers a strong sense of order. The flowers are three-

Gongbi is a kind of Chinese painting skill. Compared with Chinese freehand brushwork, it is a kind of meticulous painting.

Sun Yude: Professor Sun is the founder of Chinese freehand three-dimensional painting school. The series of lectures given by professor Sun on CETV are welcomed and praised by art lovers at home and abroad. dimensional and realistic, which fully shows the elegant temperament and thriving artistic conception of peony. The work organically combines the flowers and birds landscape with distinctive techniques. Peony as the main body, in the foreground, mountains and rivers setting off the atmosphere as the background, the picture of emotion and scenery blend, to the readers add unlimited reverie, this work creatively shows the creative style of the new era, and achieves the artistic charm of visual impact and appeal.

The three-dimensional images in paintings are also expressed relying on the light and shadow. Only when the sun shines on everything is full of vitality, Chinese painting could not avoid the expression of light and shadow, which is the difficulty of freehand brushwork technology. For example, "Hu Guang Lie Yan" and "Xiao Ri Hong Shan", these are two of Ma Yuan's twelve paintings depicting water. They respectively depict the light reflected by the sun passing through the lake surface, and clouds blocking the water bring shadow. Taking water as the main body, the author depicts different forms of water and conveys different artistic conception. These works are extremely rare in ancient China to depict the successful works of light and shadow.

\section{THE AUDIENCE OF THE THREE- DIMENSIONAL IMAGE OF CHINESE FREEHAND PAINTING AND AESTHETIC EXPECTATION}

In the Symposium on Literary and Art, General secretary Xi Jinping pointed out: "socialist literature and art, in essence, is the literature and art of the people." 9 Art creation cannot be separated from the people, art is to serve the people, so it must be peopleoriented. People's aesthetic view is always full of the characteristics of the times. People hope to see a new form of painting, beyond the limitations of national and regional, so that people all over the world could understand and appreciate it, so as to achieve the goal of global cultural sharing. Some people worry that the national characteristics will be lost. In fact, it will not. The combination of poetry, calligraphy, painting and seal of traditional Chinese painting conveys rich emotions. These elements in the painting could create novel artistic conception, which is the essence of national characteristics. China's development has shown unprecedented prosperity. Modern viewers are better at interpreting the artistic conception of painting with rational thinking and scientific attitude. They have expectations for painting according to their own aesthetics. Inheriting the tradition is not a simple repetition. There are many differences in the process of historical development and social change, which

9 Xi Jinping: Symposium on Literature and Art, 15th Oct 
"reveals the differences of understanding of painting works before and now." ${ }^{10}$ Against the background of cultural integration, the more Chinese freehand brushwork follows the predecessors and adheres to the tradition, the weaker the artistic characteristics and national characteristics will be. Benjamin believes that, like the general material production, artistic creation should also be restricted by the contradictory movement between productivity and production relations, and the "technology" in artistic creation represents the development of productivity, especially the new mechanical reproduction technology applied to artistic creation will change the traditional function of art. ${ }^{11}$ Whether it is made by machine or by hand, simple reproduction will inevitably bring visual fatigue and reduce people's aesthetic experience. The symbols of Chinese freehand brushwork need to be rich and colorful, and the composition in the painting should be bold and full of creativity, which is the call of the times.

\section{SIGNIFICANCE OF THREE-DIMENSIONAL IMAGES IN FREEHAND BRUSHWORK}

With the development of science and technology and the popularity of the Internet, the aesthetic level and cognitive ability of contemporary people have been greatly improved, and the old forms of art have been unable to meet the contemporary aesthetic needs. People are good at using rational thinking and scientific point of view to interpret art works, clarify the meaning of image symbols, and perceive the visual strength of images. Three-dimensional symbols of Chinese freehand brushwork can meet the psychological and physiological needs of the people, so as to stimulate people's aesthetic "pleasure".

\section{A. "Truth, goodness and beauty" is the symbol of three-dimensional thinking}

"The pursuit of truth, goodness and beauty is the eternal goal of art. The highest level of art is to make people feel excited, to baptize people's souls, let people discover the beauty of nature, the beauty of life and the beauty of soul. We should convey the true, the good and the beauty through literary and artistic works." 12 With the development of the times, people's aesthetic requirements for arts are gradually increasing.

However, the works created by many artists who flaunt "art for art sake" cannot bring good aesthetic experience to people. The development of painting is

10 H.R.Jauss, R.C.Holub: Receptional Aesthetic and Reception Theory, Liaoning People's Publishing House 1987, P 35.

11 Guide by Zhouying: Introduction to Art in the Age of Machine Reproduction, Tianjin People's Publishing House, 2010, P28.

12 Xi Jinping: Symposium on Literature and Art, 15th Oct. not the "self-entertainment" of "artists", but the aesthetic expectation of modern people is placed on the paintings. The three-dimensional of Chinese painting is the integration of "Tao and art", seeking the artistic realm of the unity of heaven and man, and the integration of things and me. Shi Tao, a painter of Qing Dynasty, advocated innovation and absorbed the essence of the ancients. Innovation after reform was the consistent proposition of the accomplished painters of the past dynasties. Today's young writers have a vigorous pursuit of innovation. As Shi Tao said, we depict all the things in the world by painting, and let ourselves indulge in it.

The Peony in Full Bloom Under the Bright Candle (see "Fig. 2") depicts a bright candle illuminating a blooming flower. This work shows the teacher's care for children's growth. It is a teacher's glorious duty to let the flowers of the motherland grow healthily. The flowers in full bloom and budding in the picture symbolize the children who are crying for food. They are the future of our country. The healthy growth of mind and body is very important, which needs teachers to nurture with sincere enthusiasm, letting them grow up freely and heartily. The work ("Fig. 2") shows people's good expectations for the future. It advocates the selfless spirit of self-love and love others.

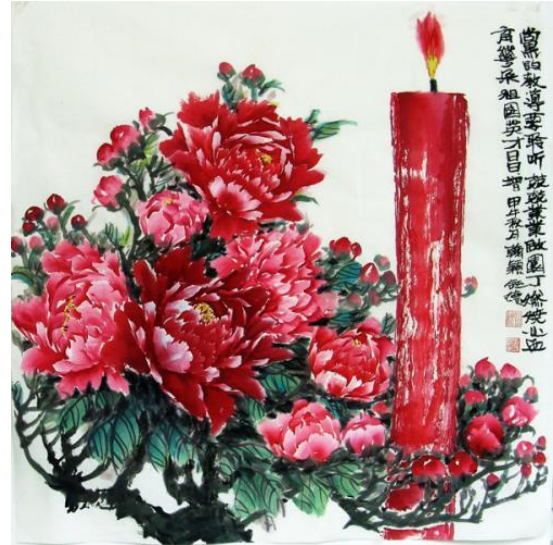

Fig. 2. Sun Hanying The Peony in Full Bloom Under the Bright Candle.

\section{B. Expanding the new artistic conception of virtual reality of Chinese painting}

Such as the work "Give a Rose to Others" There is fragrance in the hand (see "Fig. 3") shows the artistic conception of crossing time and space. Roses bloom from May to June every year, while grapes mature in August every year. These two things that could not appear at the same time are displayed on the unified picture. Through the virtual art, the existence of reality is surpassed. The exquisite and transparent grapes in the painting seem to make the viewer feel the sweetness of taste, and smell the fragrance of roses and flowers Echoing with grapes, it has crossed the spring and 
autumn seasons, forming a three-dimensional feeling of season coincidence. Through this kind of synesthesia, people can spread great love from the fragrant and sweet feelings, carry forward the positive energy, and let the viewer's various senses immerse into the painting scene.

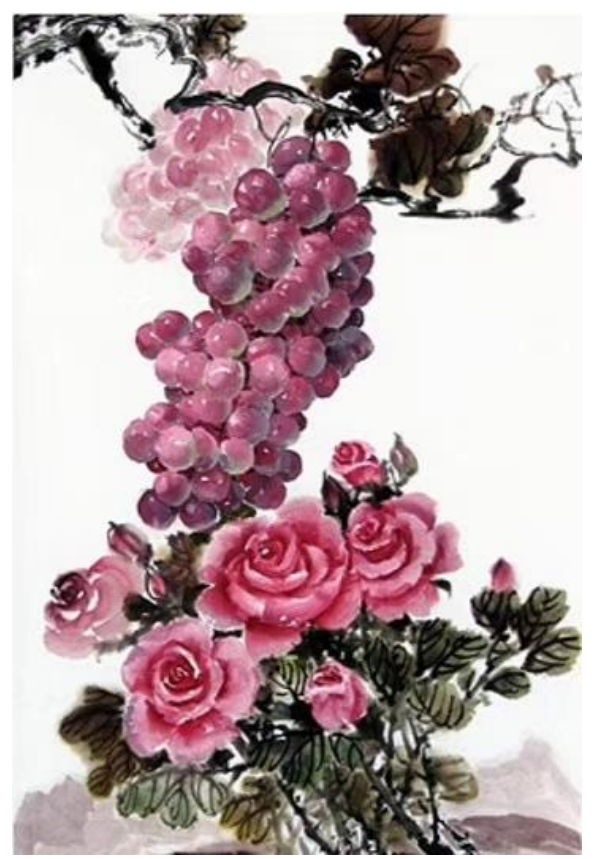

Fig. 3. Sun Yude Give a Rose to Others.

\section{CONCLUSION}

Art is like a mirror reflecting the life of the times. Traditional Chinese painting is a symbol of Chinese culture, and cannot be satisfied with the achievements of the past and the present. To inherit the foundation of traditional Chinese painting, we should pay attention to innovation, keep pace with the times and conform to the law of visual science. The Chinese freehand brushwork in the new era must be clearly distinguished from the painting features of various times in order to show the spirit of the times and provide the basis for later generations to study traditional Chinese painting history.

\section{References}

[1] Craig Clunas, Trans by Huang Xiaojuan: Pictures and Visuality in Early Modern China, Peking University Press, 2011, Beijing, China, PIX.

[2] Lin Fengmian"The Future of the Traditional Chinese Painting We Hope For" in Shao Qi, Sun Haiyan: A collection of discussions on Traditional Chinese painting in the 20th Century, Shanghai, Shanghai Calligraphy \& Painting Publishing House, 2008, P60.

[3] Hu Jun:" Research on the Brain Neural Mechanism of Literary and Artistic Creation". Social Science. 2020,(2).
[4] Xi Jinping: Symposium on Literature and Art, $15^{\text {th }}$ Oct. 2014.

[5] H·R.Jauss, R.C.Holub: Receptional Aesthetic and Reception Theory, Liaoning People's Publishing House 1987, P 35.

[6] Guided by Zhouying: Introduction to Art in the Age of Machine Reproduction,Tianjin People's Publishing House,2010,P28.

[7] Xi Jinping: Symposium on Literature and Art, 15 ${ }^{\text {th }}$ Oct. 2014. 